\title{
Fully-coupled analysis for the behaviour of flexible retaining structures under seismic conditions
}

\author{
Nicola Pontani ${ }^{1,2^{*}}$, Kateryna Oliynyk $^{2}$ and Claudio Tamagnini ${ }^{2}$ \\ ${ }^{1}$ Politecnico di Milano, piazza Leonardo da Vinci 32, 20133, Milano, Italy \\ ${ }^{2}$ Università degli Studi di Perugia, via Goffredo Duranti 06125, Perugia, Italy
}

\begin{abstract}
The study concerns the analysis of the behaviour of two propped reinforced-concrete diaphragm walls in coarse sand under seismic conditions. Fully-coupled dynamic equilibrium and pore water flow under unsaturated conditions for the soil have been taken into account, in order to assess the effects that the development of excess pore water pressures can have on the performance of such structures when dynamic conditions occur. The von Wolffersdorff hypoplastic model and the van Genuchten soil-water retention model have been used to describe the mechanical and retention behaviour of the sand. The Finite Element predictions of the soil and retaining structure behaviour show a significant dependence of the seismic performance of the structure - evaluated in terms of permanent displacements and structural loads, in view of the modern performance-based design criteria - on the excess pore pressures developed in the soil during the seismic shaking, even when dynamic liquefaction does not occur.
\end{abstract}

\section{Introduction}

Retaining structures play a crucial role in the construction of different infrastructure facilities, such as roads, railways and underground urban transportation systems. Instability or failure of such structures under seismic conditions has caused severe technical and economic problems in the past, often due to the accumulation of permanent displacements at the end of the earthquake.

This is the reason why, in the past few years, retaining structures of various kind have attracted significant attention within the scientific community, leading to both experimental and theoretical research activities, focused on the behaviour of both rigid, gravity-type walls and flexible diaphragms and sheetpiles. For the former kind of structures, the current design criteria, based on the conventional (force-based) pseudo-static approach or, more recently, on the (displacement-based) Newmark's method, typically allow a satisfactory assessment of the wall response under seismic loading conditions [1].

This is not true for flexible retaining walls, whose behaviour might be strongly affected by the deformation of both the wall itself and the soil. Furthermore, the presence of variable (in both time and space) pore water pressure field should be taken into account, in order to quantify the effects of hydro-mechanical coupling on both soil and wall behaviour, including the possibility of triggering dynamic liquefaction. These factors cannot be considered merely using the traditional analysis methods and the use of numerical tools (e.g., the Finite Element
Method) is needed. The computational cost of such advanced techniques is well balanced by the possibility to adopt a fully coupled hydro-mechanical setting and to use advanced non-linear constitutive models capable of reproducing the main features of the cyclic/dynamic behaviour of soils.

The aim of this work is to provide a contribution to the better understanding of the complex soil-structure interaction processes which occur during the earthquake excitation due to hydro-mechanical coupling processes, with particular emphasis on the development of excess pore pressures, as the ratio $R_{T}$ between the characteristic time associated to the time-dependent inertia forces in the soil mass and the characteristic time associated to excess pore pressure dissipation is varied between the two extremes of fully undrained behaviour $\left(R_{T} \rightarrow 0\right)$ and fully drained behaviour $\left(R_{T} \rightarrow \infty\right)$.

To this end, a number of nonlinear, fully coupled FE simulations of an ideal, but realistic, retaining structure subjected to an earthquake have been carried out in parametric form, as detailed in the following sections.

\section{Problem setting and seismic input}

The problem considered is represented in Fig. 1. It consists of a deep excavation, with height $H=8.0 \mathrm{~m}$ and half-width $B=9.0 \mathrm{~m}$, supported by a pair of reinforced concrete diaphragm walls propped at the crest, hinged at a depth $a=0.5 \mathrm{~m}$ from the ground surface. The walls embedment depth $d$ has been set to $6.0 \mathrm{~m}$, so that the safety level under static loads complies with the current Italian design norms [2]. 


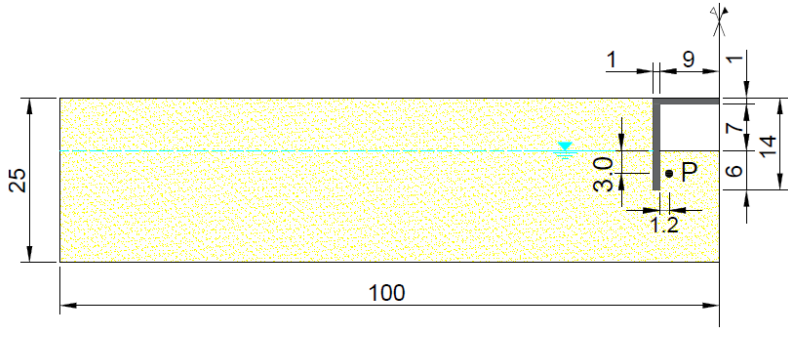

Fig. 1. Problem geometry (values in $\mathrm{m}$, only half of the domain is shown).

The soil layer of homogeneous loose sand is $25 \mathrm{~m}$ thick and is underlain by a rigid, impervious bedrock. The initial conditions for the pore water pressures are assumed hydrostatic, with the piezometric surface located at a depth of $8.0 \mathrm{~m}$ below the ground surface (corresponding to the bottom of the excavation).

One of the accelerograms recorded during the 1997 Umbria-Marche earthquake in Assisi (NS component) [3] has been adopted as the seismic input at the bottom of the soil layer (Fig. 2). Baseline correction has been performed to correct for the spurious effects of data sampling.

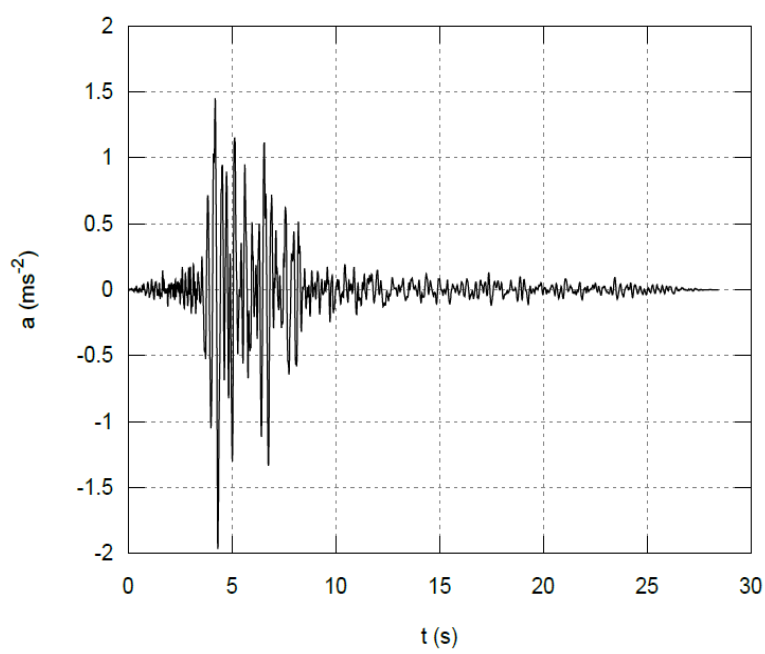

Fig. 2. Acceleration time-history of the seismic input at the bedrock.

Relevant ground motion characteristics (peak acceleration, $a_{\max }$, fundamental period, $T$, predominant frequency, $f$, Arias intensity, $I_{A}$, duration, $t_{\mathrm{d}}$ ) of the Assisi earthquake are summarized in Table 1.

In order to quantify the expected seismic performance of the retaining structure, in the following the attention will be focused on the permanent horizontal displacements accumulated by the diaphragm walls at the end of the earthquake.

Table 1. Representative properties of the seismic input.

\begin{tabular}{cccccc}
\hline & $\begin{array}{c}a_{\max } \\
(\mathrm{g})\end{array}$ & $\begin{array}{c}T \\
(\mathrm{~s})\end{array}$ & $\begin{array}{c}f \\
(\mathrm{~Hz})\end{array}$ & $\begin{array}{c}I_{A} \\
(\mathrm{~m} / \mathrm{s})\end{array}$ & $\begin{array}{c}t_{d} \\
(\mathrm{~s})\end{array}$ \\
\hline Assisi NS & 0.2 & 0.32 & 3.13 & 4.14 & 0.264 \\
\hline
\end{tabular}

\section{Soil constitutive model}

In order to take into account the principal features of the mechanical response of coarse-grained soils under cyclic and dynamic loading conditions, e.g. non-linearity, irreversibility, dependence on pressure and density (barotropy and pyknotropy), stress- and stress historydependent dilatancy, the hypoplastic constitutive model proposed by von Wolffersdorff $(\mathrm{vW})$ has been adopted in this work [4]. The model is characterized by a relatively simple mathematical structure and is based on a small set of material constants, which can be determined by means of conventional laboratory tests. To incorporate the memory of the recent deformation history, a tensorial internal variable - the so-called "Intergranular Strain" -has been added to the set of state variables, as suggested by Niemunis \& Herle [5]. The recent modifications proposed by Wegener \& Herle [6] have been adopted to avoid excessive ratchetting under small amplitude cycles.

Under the assumption of linear kinematics, the constitutive equation of the model assumes the following general format:

$$
\stackrel{\&}{=} \mathbf{D}\left(\boldsymbol{\sigma}, e, \boldsymbol{\delta}, \boldsymbol{\eta}_{\varepsilon}\right) \&
$$

where the tangent stiffness $\mathbf{D}$ (a fourth-order tensor) is a function of the current state - effective stress, $\boldsymbol{\sigma}$, void ratio, $e$, and intergranular strain $\boldsymbol{\delta}$ - and of the strain rate direction, $\eta_{\boldsymbol{\varepsilon}}$. Homogeneity of degree 0 of the tangent stiffness with respect to the strain rate implies the rateindependence of the constitutive model. Therefore, energy dissipation in the soil during cyclic loading is due to hysteretic effects only.

The set of constants provided by Herle for Toyoura Sand [7] has been used to describe the mechanical properties of the soil (Tab. 2).

Table 2. Constants of von Wolffersdorff model for Toyoura sand (after ref. [7]).

\begin{tabular}{ccccccc}
\hline $\begin{array}{c}\varphi_{c} \\
(\mathrm{deg})\end{array}$ & $\begin{array}{c}h_{s} \\
(\mathrm{kPa})\end{array}$ & $\begin{array}{c}n \\
(-)\end{array}$ & $\begin{array}{c}e_{d 0} \\
(-)\end{array}$ & $\begin{array}{c}e_{c 0} \\
(-)\end{array}$ & $\begin{array}{c}e_{i 0} \\
(-)\end{array}$ & $\begin{array}{c}\alpha \\
(-)\end{array}$ \\
\hline 30.0 & $2.6 \mathrm{e} 6$ & 0.27 & 0.61 & 0.98 & 1.10 & 0.18 \\
\hline \hline $\begin{array}{c}\boldsymbol{C} \\
(-)\end{array}$ & $\begin{array}{c}R \\
(-)\end{array}$ & $\begin{array}{c}m_{R} \\
(-)\end{array}$ & $\begin{array}{c}m_{T} \\
(-)\end{array}$ & $\begin{array}{c}\beta_{R} \\
(-)\end{array}$ & $\begin{array}{c}\chi \\
(-)\end{array}$ & $\begin{array}{c}\vartheta \\
(-)\end{array}$ \\
\hline 1.10 & $1.0 \mathrm{e}-4$ & 5.0 & 2.0 & 0.12 & 1.0 & 10.0 \\
\hline
\end{tabular}

The extension of the model to unsaturated states is achieved by extending the definition of "effective" stress following, for example, [8]:

$$
\boldsymbol{\sigma}=\boldsymbol{\tau}-\left\{\left(1-S_{r}\right) u_{g}+S_{r} u_{w}\right\} \mathbf{1}=\boldsymbol{\tau}-S_{r} u_{w} \mathbf{1}
$$

where $\tau$ is the total stress, $\mathrm{u}_{\mathrm{g}}$ and $u_{w}$ are the pressure of pore gas (assumed equal to zero throughout) and pore water, respectively, and $S_{r}$ is the degree of water saturation.

The van Genuchten model [9] is adopted to link the degree of saturation $S_{r}$ to the suction $s=u_{g}-u_{w}$ and the 
relative permeability of the soil, $k_{\text {rel }}$, to its degree of saturation:

$$
\begin{gathered}
S_{r}(s)=S_{r, \text { res }}+\left(S_{r, \text { sat }}-S_{r, \text { res }}\right)\left\{1+\left[\frac{g_{a} s}{\rho_{w} g}\right]^{g_{n}}\right\}^{\left(1-g_{n}\right) / g_{n}} \\
k_{\text {rel }}\left(S_{e}\right)=\left(S_{e}\right)^{g_{l}}\left\{1-\left[1-\left(S_{e}\right)^{g_{n} /\left(g_{n}-1\right)}\right]^{\left(g_{n}-1\right) / g_{n}}\right\}^{2} \\
S_{e}=\frac{S_{r}-S_{r, \text { res }}}{S_{r, \text { sat }}-S_{r, \text { res }}}
\end{gathered}
$$

The constants adopted for the van Genuchten model have been derived from the experimental data provided in Lu and Likos [10] for a medium to coarse sand (Fig. 3 ) and are shown in Table 3.

Table 3. Constants of the van Genuchten model.

\begin{tabular}{ccccc}
\hline $\begin{array}{c}S_{r, \mathrm{res}} \\
(-)\end{array}$ & $\begin{array}{c}S_{r, \mathrm{sat}} \\
(-)\end{array}$ & $\begin{array}{c}g_{l} \\
(-)\end{array}$ & $\begin{array}{c}g_{a} \\
(-)\end{array}$ & $\begin{array}{c}g_{n} \\
(-)\end{array}$ \\
\hline 0.121 & 1.00 & -0.14 & 3.10 & 4.00 \\
\hline
\end{tabular}

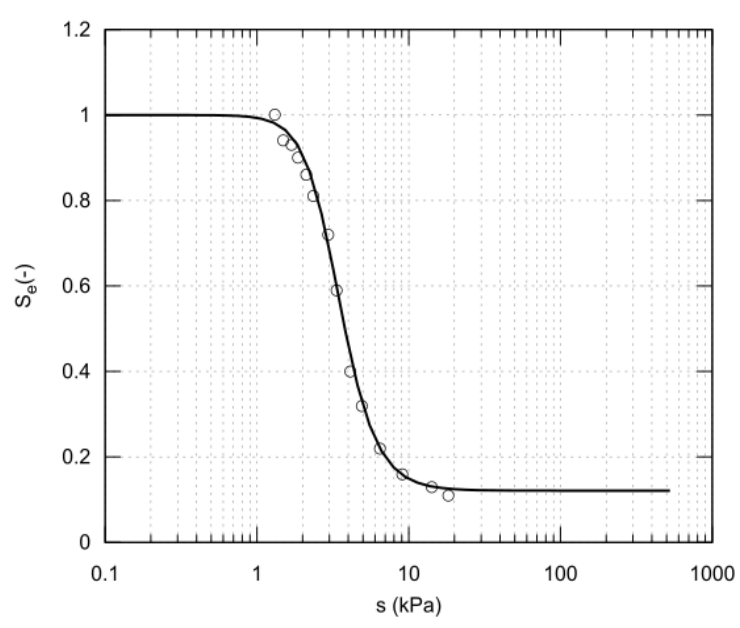

Fig. 3 Adopted soil water retention curve (data from [10]).

Concerning the structural elements (the two diaphragm walls and the strut), a linear elastic constitutive model has been used, with a Young modulus of $2.0 \mathrm{e} 7 \mathrm{kPa}$ and a Poisson's ratio of 0.25 .

\section{Finite element model}

The FE simulations have been performed with the research-oriented code Tochnog Professional. The spatial discretization of the domain is shown in Fig. 4. Bilinear Q4P4 isoparametric solid elements with 4 nodes for both displacement and pore pressure fields have been used for the soil. In order to have independent pore water pressure fields on the left and right sides of the diaphragm walls, bilinear Q4P0 elements with displacements degrees of freedom only have been used for the two walls. Finally, Q2 linear truss-beam elements have been used to model the strut.

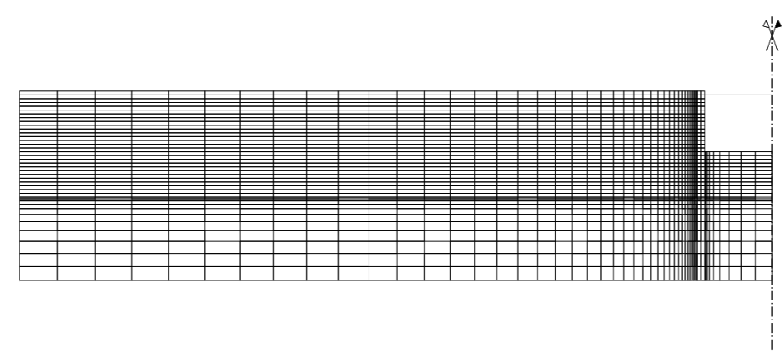

Fig. 4. Finite element discretization adopted (only half domain is shown).

The initial, geostatic conditions for the single layer of sand have been assumed as loose of critical, with a constant relative density (defined in terms of $e_{i}$ and $e_{d}$ ) for the entire soil layer. This is obtained by fixing a costant distance between the critical void ratio (as defined by the von Wolffersdorff model [4]) and the initial void ratio, as shown in Fig. 5.

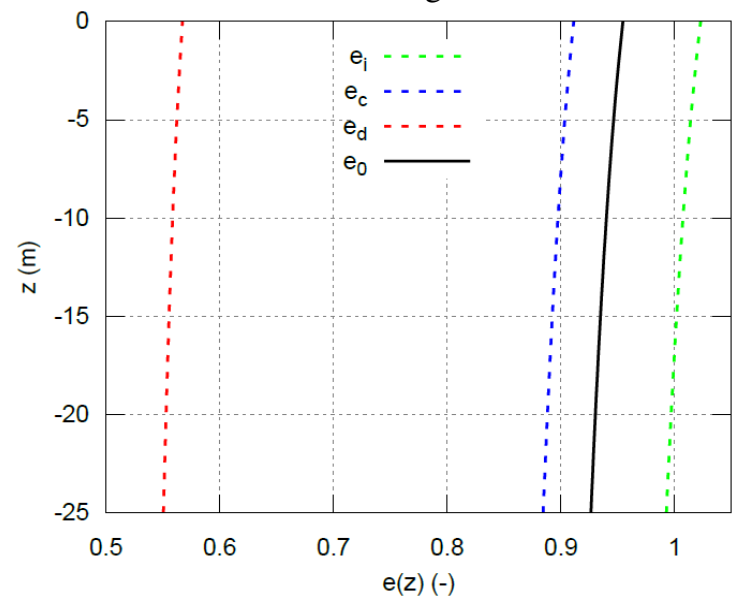

Fig. 5. Initial conditions for the void ratio.

The reconstruction of the soil and wall conditions before the start of the earthquake has been carried out by modelling the excavation up to the final depth in a quasistatic simulation carried out under drained conditions.

For each dynamic simulation, the following boundary conditions have been imposed:

- periodic boundary conditions on the vertical lateral sides for the pore pressure and velocity fields;

- imposed time history of the horizontal acceleration with zero vertical velocity at the bedrock (bottom of the soil layer);

- non positive pore water pressure at the ground surface and at the bottom of the excavation (i.e., outward flow allowed at pressure $u_{w}=0$ ).

In order to investigate the effects of pore water pressure build-up and dissipation during the seismic shaking, five numerical simulations have been carried out, varying the saturated hydraulic conductivity of the soil in the range $3.0 \mathrm{e}-4$ to $3.5 \mathrm{e}-2 \mathrm{~m} / \mathrm{s}$, as shown in Table 4. The highest value of the saturated hydraulic conductivity (simulation r1) corresponds roughly to the "drained" limit, as the excess pore pressures dissipation is so rapid that no significant changes in the initial hydrostatic distribution is observed during the earthquake event. In all the other cases, the pore pressure dissipation is not sufficiently rapid to prevent significant 
excess pore pressure build-up, with less and less "drainage" moving from r2 to r5.

Table 4. Program of FE simulations.

\begin{tabular}{cccccc}
\hline Simulation & $\mathrm{r} 1$ & $\mathrm{r} 2$ & $\mathrm{r} 3$ & $\mathrm{r} 4$ & $\mathrm{r} 5$ \\
\hline$k_{\mathrm{sat}}(\mathrm{m} / \mathrm{s})$ & $3.5 \mathrm{e}-2$ & $1.6 \mathrm{e}-2$ & $8.0 \mathrm{e}-3$ & $4.0 \mathrm{e}-3$ & $3.0 \mathrm{e}-4$ \\
\hline
\end{tabular}

\section{Numerical results}

The time histories of the horizontal displacements at the base of the wall (Fig. 6) show that the permanent displacements accumulated depend in a significant way on the soil hydraulic conductivity. The smaller is $k_{\text {sat }}$, the greater are the residual displacements (in absolute terms). For the highest values of the hydraulic conductivity, the seismic performance of the walls is comparable with the one observed under fully drained conditions, with a maximum permanent displacement around $10 \mathrm{~cm}$. On the contrary, the structural performance computed for the lower values of $k_{\text {sat }}$, with final displacements in the range 30 to $40 \mathrm{~cm}$, cannot be considered satisfactory. The very large displacements accumulated in simulation r5 suggest that the retaining structure is on the verge of failure, possibly due to partial or total liquefaction of the soil below the bottom of the excavation.

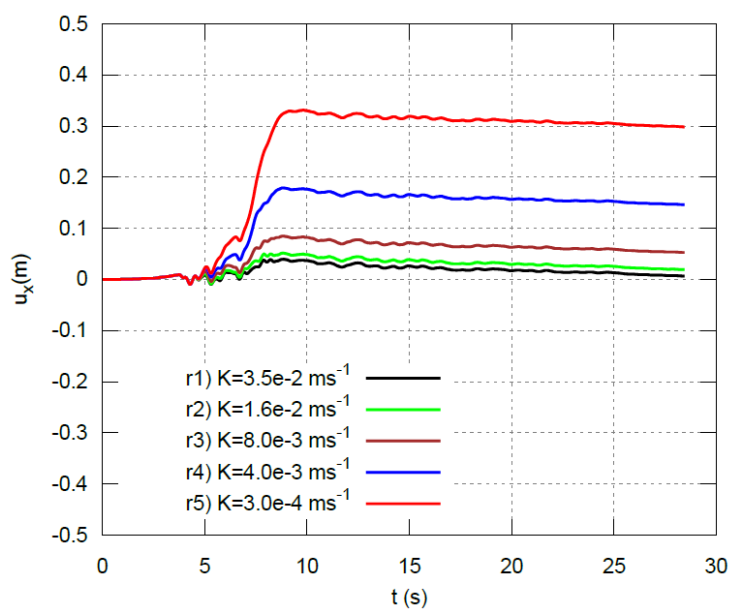

Fig. 6. Time history of the horizontal displacements at the base of the left wall (positive values correspond to inward displacements).

The post-seismic maximum horizontal displacements computed in each simulation, normalized with respect to the maximum displacement at the same point computed in simulation r1 ("drained" limit), are shown as a function of the ratio $k_{\text {sat }} / k_{\text {sat,max }}$ in Fig. 7.

It is apparent how the seismic performance of the retaining structure deteriorates rapidly as permeability decreases, with a $400 \%$ increase for a two order of magnitude reduction in $k_{\text {sat }}$. Taking as an acceptable measure of seismic performance a maximum displacement of about $10 \mathrm{~cm}$, it is clear from the figure that the seismic safety level of the structure is - for the same soil and identical initial conditions - acceptable in the cases $\mathrm{r} 1$ and $\mathrm{r} 2$, and not acceptable in all the other cases.

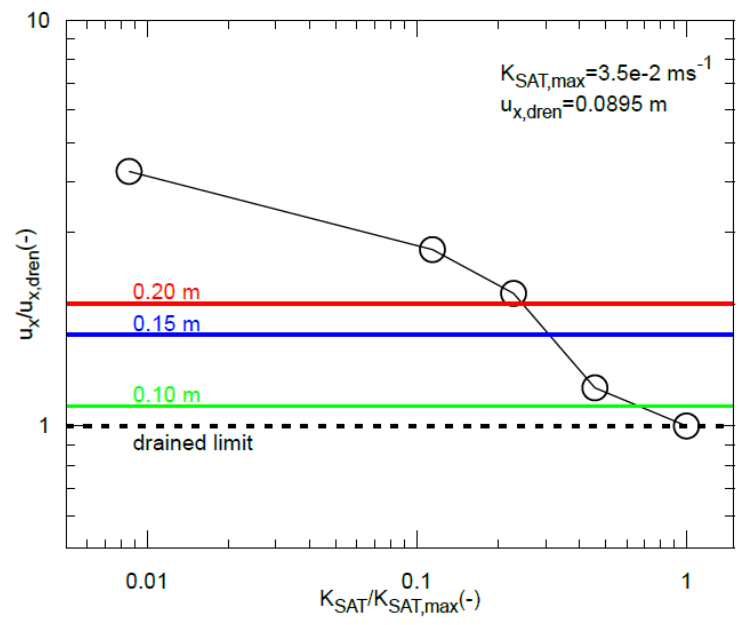

Fig. 7. Seismic performance of the retaining structures.

The final deformed configurations of the left wall and the bending moment distributions are shown in Fig. 8. In the figure, $m$ is the ratio between the bending moment and the maximum value recorded among all the simulations, while $U_{x}$ and $Z$ represent the horizontal displacements of the wall (positive rightwards) and the depth from ground surface (positive upwards), normalized with respect to the height $H$ of the wall.

From the results in Fig. $8 \mathrm{a}$ it is clear that the wall tends to behave as a rigid body rotating around the strut when $k_{\text {sat }}$ decreases, while significant bending occurs at larger permeability values. Therefore, computed bending moments tend to increase as $k_{\text {sat }}$ increases (Fig. 8b).

The observed significant impact that soil hydraulic conductivity has on the displacements of the soil and of the retaining structure may be interpreted considering the space and time evolution of the pore pressure field during the earthquake. Fig. 9 shows the time histories of the excess pore water pressure $\Delta p_{w}=u_{w}-u_{w 0}$ at point $\mathrm{P}$ in Fig 1, for the simulations $r 1$ (largest permeability), r3 (intermediate permeability) and $\mathrm{r} 5$ (lowest permeability). From the data it is apparent that the generation of positive excess pore pressure induced by the tendency of the soil to contract under shear is contrasted by the tendency of the water to move inside the porous media, which is accompanied by excess pore pressure dissipation. When the permeability is high, the dissipation of $\Delta p_{w}$ takes place in a time span comparable to the duration of the seismic excitation, thus resulting in a low maximum value of $\Delta p_{w}$ and in its complete dissipation before the end of the earthquake.

On the other hand, when the permeability is low, excess pore pressure dissipation requires consolidation times which are order of magnitude larger than the earthquake duration, so that the peak $\Delta p_{w}$ remains almost unchanged at the end of the shaking. It is only under such conditions that the two processes of (undrained) excess pore pressure generation during the seismic stage and its dissipation in a (quasi-static) consolidation process can be analysed independently (separation of time-scales). 


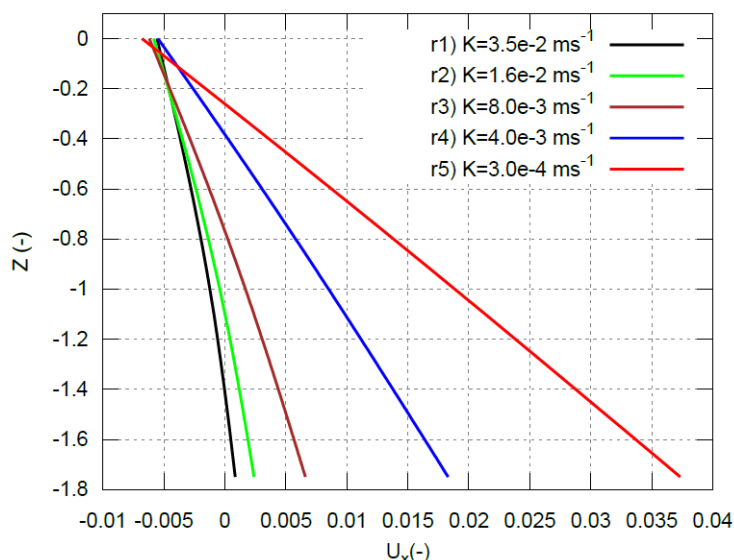

(a)

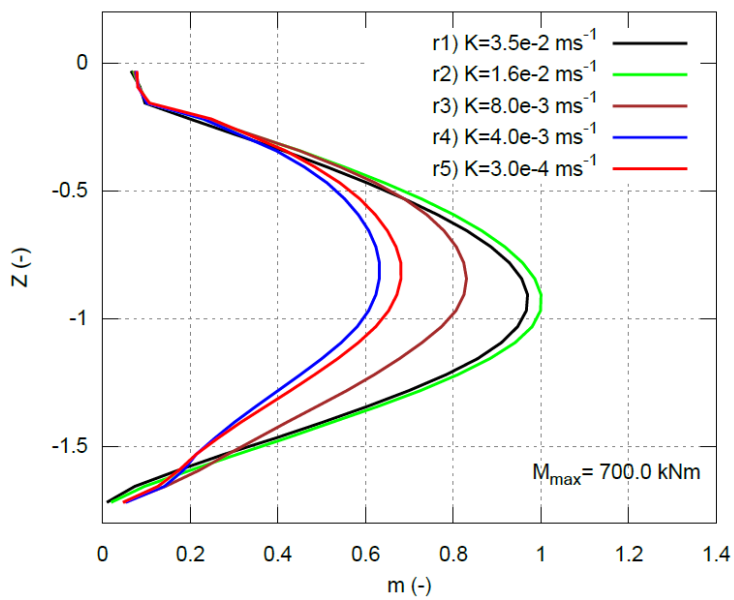

(b)

Fig. 8. Deformed configurations and normalized bending moment distributions for the left wall at the end of the seismic stage.
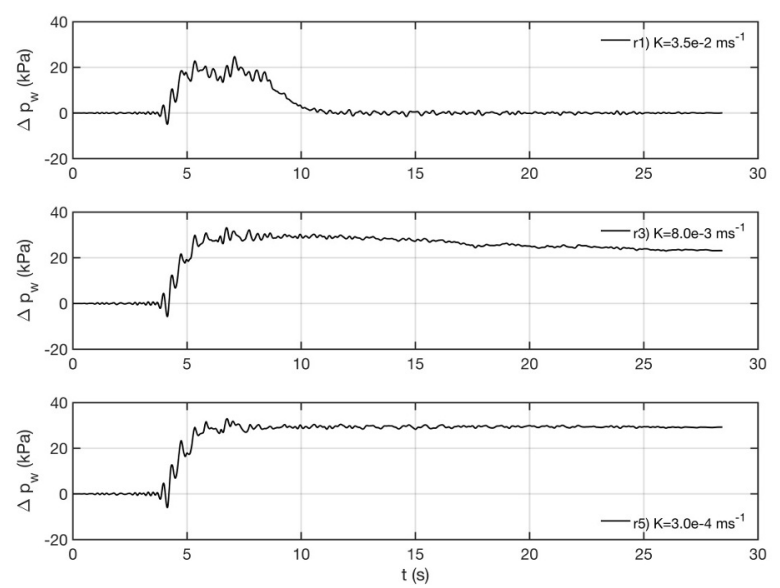

Fig. 9. Time histories of $\Delta p_{w}$ at point $\mathrm{P}$ in Fig. 1.

A more complete picture of the spatial distribution of excess pore pressures computed in simulations $\mathrm{r} 1$ and $\mathrm{r} 5$ is provided by Figs. 10 and 11, showing the contour maps of the modified hydraulic head $h^{*}=\rho_{w} g h$ at four different times during the earthquake loading stage. The choice of representing this particular quantity is motivated by the fact that $h^{*}-h_{0}^{*}=\Delta p_{w}$, so it easy to visualize the regions where large excess pore pressures occur (considering that the initial value $h_{0}^{*}=167 \mathrm{kPa}$ ).

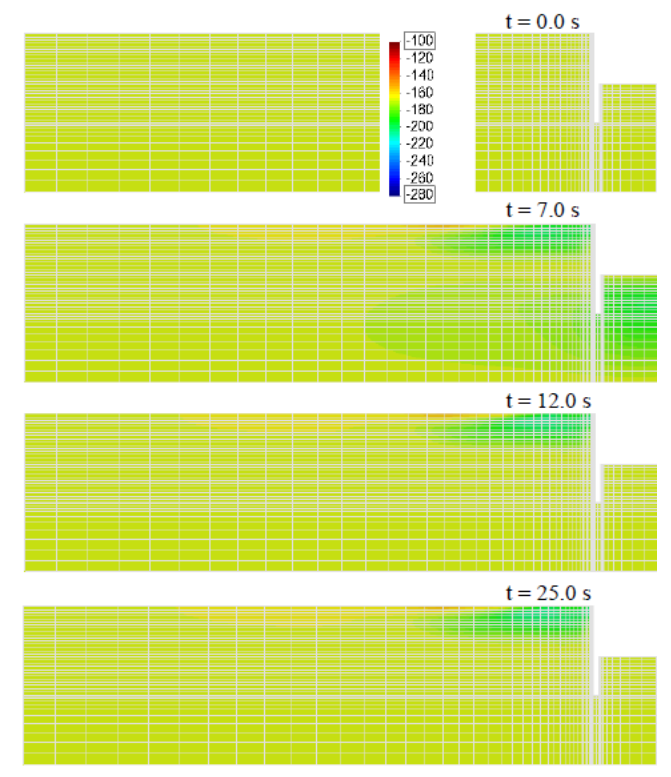

Fig. 10. Simulation $\mathrm{r} 1\left(k_{\mathrm{sat}}=3.5 \mathrm{e}-2 \mathrm{~m} / \mathrm{s}\right)$ : modified hydraulic head $h^{*}$ at different time stations during the seismic stage (values negative in compression).

In simulation r1 (Fig. 10), non-negligible excess pore pressures (about $20 \mathrm{kPa}$ on average) develop in the first $10 \mathrm{~s}$ of the excitation below the excavation level and at the back of the wall, in correspondence to the strut.

In the saturated zone of soil below the excavation, the dissipation of $\Delta p_{w}$ is so fast that by the end of the earthquake the pore pressures have returned to their initial value. The reduction in effective stress experienced by the soil - and thus in the earth thrust on the passive side of the wall - is relatively small and occurs only for a limited amount of time, during which the permanent displacements accumulated are small. It is interesting to note that the excess pore pressure dissipation close to the ground surface is not so fast, due to the fact that the low degree of saturation of the soil reduces its permeability by several orders of magnitude, thus slowing significantly the dissipation process. However, the effect on the wall behaviour is small as this zone of soil is located close to the strut.

On the contrary, in simulation r5 (Fig. 11) much larger excess pore pressures are observed (about $50 \mathrm{kPa}$ max) again below the excavation level and at the back of the wall, in correspondence to the strut. In this case the dissipation of $\Delta p_{w}$ is significantly slower, so that most of the accumulated excess pore pressures are still present at the end of the earthquake, even in the saturated zone below the excavation level.

In cohesionless soils, when the increase of excess pore pressure is such to determine the reduction to almost zero of the mean effective stress, a condition of dynamic liquefaction is reached where the stiffness and shear strength of the soil both tend to zero. The plots in Fig. 12, showing the contour maps of the minimum (maximum negative) effective stress computed in simulation $\mathrm{r} 5$ at various time instants, indicate that this is what has actually occurred to the soil below the excavation level, where liquefaction $\left(\sigma_{3}=0\right)$ is observed starting from $t=7 \mathrm{~s}$. Under such conditions, the walls 
loose almost completely any support from the soil on the passive side - apart from a hydrostatic pressure contribution from the fluidized soil - and can rotate freely under the action of the earth thrust on the active side.

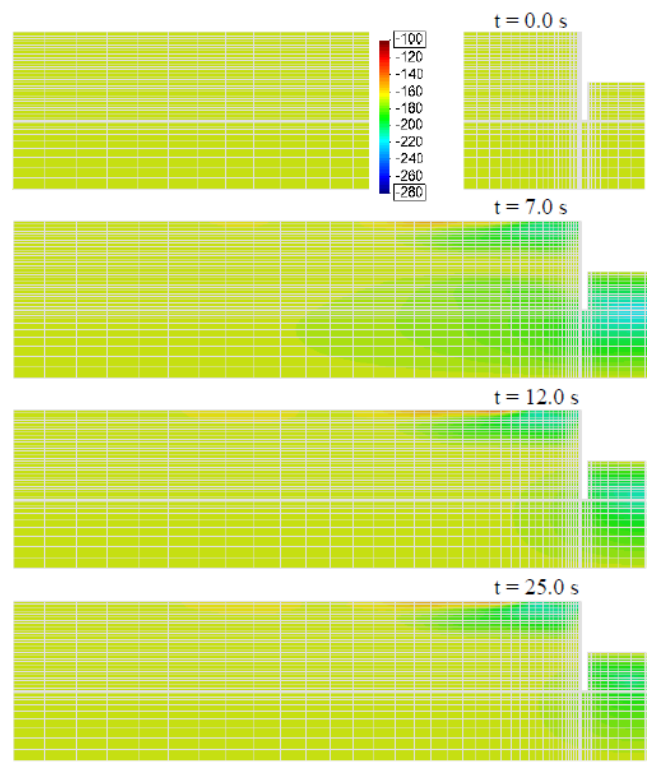

Fig. 11. Simulation $\mathrm{r} 5\left(k_{\mathrm{sat}}=3.0 \mathrm{e}-4 \mathrm{~m} / \mathrm{s}\right)$ : modified hydraulic head $h^{*}$ at different time stations during the seismic stage (values negative in compression).

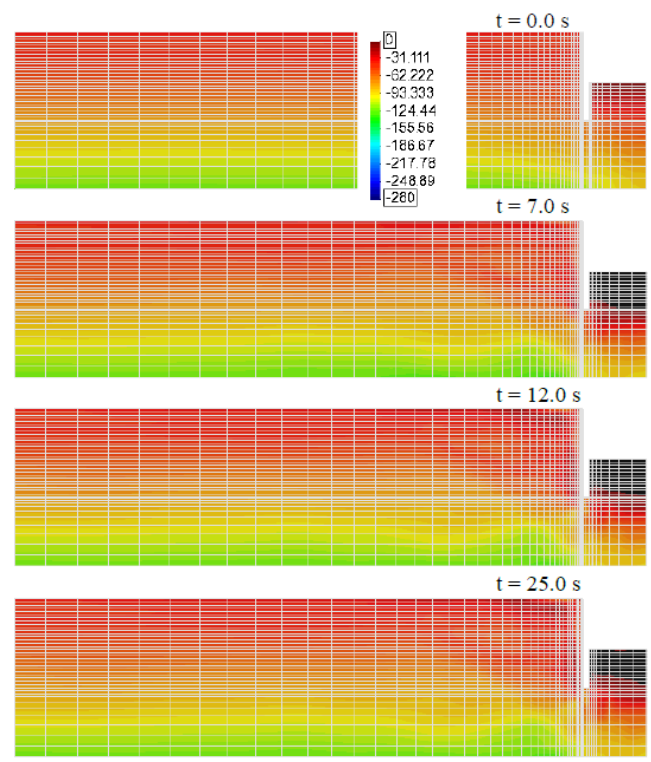

Fig. 12. Simulation $\mathrm{r} 5\left(k_{\mathrm{sat}}=3.0 \mathrm{e}-4 \mathrm{~m} / \mathrm{s}\right)$ : contour maps of $\sigma_{3}$ at different time stations during the seismic stage (values negative in compression).

\section{Conclusions}

The results of the parametric study carried out in this work show the dramatic impact that excess pore pressure generation might have on the seismic performance of flexible retaining structures in sands. In particular, it has been shown that a relatively small decrease of the hydraulic conductivity (roughly two orders of magnitude) can be sufficient to bring a structure whose seismic performance would be perfectly acceptable under dry soil or "drained" conditions to a condition of failure due to dynamic liquefaction. However, it is important to stress that the build-up of excess pore water pressures could bring the structure to an unsafe state even in situations where liquefaction does not occur, as in cases $\mathrm{r} 3$ and $\mathrm{r} 4$.

The possibility of predicting accurately the evolution of $u_{w}$ within the soil mass in space and time is strongly related to two fundamental factors: the ability of the constitutive model adopted to reproduce the dilatant/contractant behaviour of the soil during the seismic loading, and the casting of the seismic analysis as a fully coupled equilibrium and flow problem of dynamic consolidation. In this respect, the conventional approaches of considering the deformation process as fully drained or fully undrained may result in either unsafe or too conservative predictions of the structure performance, especially when including unsaturated conditions.

\section{References}

1. R. V. Whitman. Seismic design and behaviour of gravity retaining walls. (Design and performance of earth retaining structures. ASCE, 1990).

2. Ministry of Infrastructures: Decree 17/01/2018 Construction Design Code Update. G.U. (in Italian).

3. G. Scasserra, G. Lanzo, J.P. Stewart, B. D'Elia. AIP Conference Proceedings, 1020, 1649 (2008).

4. P.A. von Wolffersdorff. Mech. Coh. Fric. Mat. 1, 251-271 (1996).

5. A. Niemunis, I. Herle. Mech. Coh. Fric. Mat. 2, 279-299 (1997).

6. D. Wegener, I. Herle. Geotechnik 37, 2, 113-122 (2014).

7. I Herle. Hypoplastizität und Granulometrie von Korngerüsten. PhD thesis Technische Universität Karlsruhe (1997).

8. B. Schrefler. The finite element method in soil consolidation (with applications to surface subsidence). Ph.D. thesis University College of Swansea (1984).

9. M. T. van Genuchten. Soil Sci. Soc. Am. J. 44, 5, 892-898 (1980).

10. N. Lu, W. J. Likos. Unsaturated Soil Mechanics (Wiley, 2004). 